\title{
Chemical Biology of Pluripotent Stem Cells: Focus on Cardiomyogenesis
}

\author{
Jijun $\mathrm{Hao}^{2}$, Li Zhou ${ }^{2}$ and Charles C. Hong 1,2,3,4,5,6 \\ ${ }^{1}$ Research Medicine, Veterans Affairs TVHS, Nashville, TN 37212 \\ 2Division of Cardiovascular Medicine, Department of Medicine, \\ ${ }^{3}$ Department of Pharmacology, \\ ${ }^{4}$ Departmetn of Cell and Developmental Biology, \\ ${ }^{5}$ Vanderbilt Institute of Chemical Biology, \\ ${ }^{6}$ Vanderbilt Center for Stem Cell Biology, \\ Vanderbilt University School of Medicine, Nashville, TN 37232,
}

USA

\section{Introduction}

Heart disease is one of the leading killers in the world and accounts for $36 \%$ of all deaths in the United States. Unlike many other organs, the heart lacks the capacity to significantly regenerate new tissues to replace those lost to injury. Consequently, ischemia, viral infection, or other insults can lead to permanent loss of cardiac tissue and irreversible heart failure. Currently, the only definitive treatment for heart failure is heart transplantation, which is precluded from wider use due to the limited availability of donor organs. In the past several years, stem cell-based regenerative therapy has emerged as a potentially promising approach to treat heart failure. Its basic goal is to replace the damaged noncontractile scar tissue with functioning cardiomyocytes derived from pluripotent or multipotent stem cells. For many years, it was generally believed that heart is a terminally differentiated organ lacking capacity to replace cardiomyocytes lost to injury. Recent studies, however, have provided evidence for limited cardiomyocyte renewal in both mice and humans [1,2]. Moreover, major inroads have been made towards understanding the nature of endogenous progenitor cells within the heart [3-5]. Although the definitive identification of the cardiac progenitor cells remains elusive, evidence of the heart's regenerative capacity, however minimal, gives hope that cell-based therapies could become a viable approach to treat human heart failure.

Among the various cell types considered for transplantation, the pluripotent embryonic stem cells (ESCs) are thought to be most suitable for the role of potentially unlimited reservoir of replacement cells given their ability to differentiate into any cell type in the body, including vascular and heart muscle cells. Following the isolation of the first human embryonic stem cell (hESC) line in 1998 [6], there has been intense interest in trying to direct differentiation of ES cells toward cardiovascular lineages, with the ultimate goal of using hESC-derived cardiomyocytes for transplantation. However the use of hESCs faces two 
major obstacles: 1) the ethical issues concerning the use of human fertilized embryos, and 2) immune rejection following transplantation. In light of this, there has been tremendous excitement over the recent development of induced pluripotent stem cells (iPSCs). In 2006, Yamanaka and colleagues demonstrated that introduction of four transcription factors (Sox2, Oct4, Klf4 and c-Myc) into fibroblasts could reprogram these cells into pluripotent iPSCs that closely resemble ESCs [7]. Cellular reprogramming has potential to revolutionize the field of regenerative medicine, since iPSCs engineered from a patient's own cells could circumvent the core ethical and immune rejection problems associated with human ES cells. The discoveries of endogenous regenerative processes and iPSCs raise hope not only for replacement of damaged heart tissues with patient-derived cardiomyocytes but also for development of new cellular models to study the pathogenesis of human heart diseases [7-12].

Despite these advances, the future use of pluripotent stem cells for diagnosis and therapy faces a number of major obstacles. For instance, the stem cell field in general has been hampered by lack of simple and robust methodologies that give consistent results. Current methods typically utilize exogenous proteins and feeder cell layers to maintain the pluripotency of stem cells. While traditional culture conditions are amenable to typical laboratory use, the dependence on expensive biological reagents limits the scale to which these cells can be cultured. Furthermore, there is often considerable variability associated with the use of growth factors, cytokines and protein antagonists. In many respects, small molecules are superior to conventional protein effectors: they are far less expensive and often yield more reproducible results. Finally, from industrial and biotechnological perspectives, small molecules are attractive intellectual property assets that can provide protection of investments in regenerative medicine. These issues have helped to set the stage for the development of small molecular modulators for use in stem cell field. In this chapter, we will provide an overview of the use of small molecules for stem cell maintenance, cellular reprogramming and directed differentiation, with a focus on cardiomyocyte formation.

\section{Role of small molecules in stem cell field.}

\section{A. Small molecules for stem cell maintenance.}

As previously mentioned, an important challenge of using pluripotent stem cells involves devising culture conditions that ensure self renewal through the maintenance of both proliferative capacity and pluripotency. ES cells are traditionally maintained on an inactivated mouse embryonic fibroblast feeder layer in medium containing undefined animal serum and exogenous proteins. For example, mouse ES cells (mESCs) require LIF (Leukemia Inhibitory Factor) to inhibit differentiation and promote cell cycle progression. Human ES cells (hESCs), which are unresponsive to LIF, require Transforming growth factor- $\beta$ (TGF- $\beta$ )/Nodal and Basic Fibroblast Growth Factor (bFGF) for maintaining pluripotency [13].

An important issue with the traditional methods of maintaining pluripotent stem cells involves the use of undefined animal serum and feeder layers, which can produce variable and heterogeneous results. Moreover, the use of animal serum products precludes clinical applications given the potential for xenoantigen introduction [14]. To overcome these obstacles, a number of serum and feeder replacement media formulations have been developed. These include KnockOut Serum Replacement, a defined media, which provides 
consistent growth conditions for maintaining ES and iPS cells [15], and mTeSR, a media specifically formulated to maintain human ESCs and iPSCs in serum-free and feeder-free conditions [16]. However, both KnockOut Serum Replacement and mTeSR require the use of animal-derived matrices and recombinant proteins, which increase costs and introduce variability [14, 17]. Consequently, there has been considerable interest in replacing exogenous proteins with chemically defined conditions for the long-term maintenance of human pluripotent stem cells.

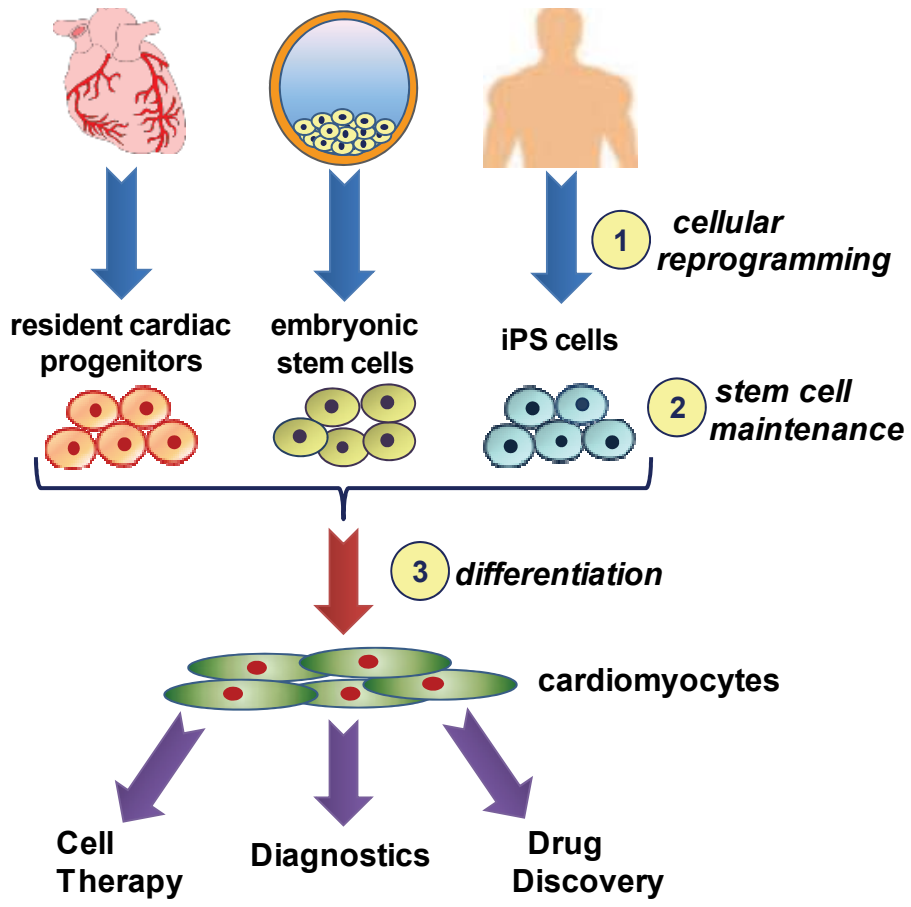

Fig. 1. Application of small molecules for stem cell-based efforts in cardiology.

Small molecules to 1) enhance reprogramming of adult somatic tissues into pluripotent stem cells, 2) maintain pluripotent stem cells in culture, and 3) promote cardiac differentiation of stem cells will be valuable for harnessing the full potential of stem cells in regenerative therapy, human cardiac tissue-based diagnostics, and drug discovery.

In a high-throughput chemical screen, Ding and colleagues identified a novel molecule, Pluripotin/SC1, which was useful for maintaining long-term self-renewal of mouse ES cells (mESCs) in the absence of a feeder layer, serum, leukemia inhibitory factor (LIF) or BMP4 [18]. The mechanism of action was found to be independent of known self-renewal pathways thought to be essential (BMP4/Smad-Id [19], Wnt/B-catenin [20], LIF/STAT3 [21]). Instead, pluripotin was characterized as a dual inhibitor of extracellular signalregulated kinase-1 (ERK1) and RasGAP, two differentiation-inducing proteins. Blocking RasGAP improves the self-renewal capabilities of ES cells by enhancing the phophonositide3 kinase (PI3K) pathway [22]. In contrast, ERK1 inhibition works by blocking ES cell differentiation $[23,24]$. 
The pluripotin discovery has important implications for stem cell renewal. The mechanism of action of pluripotin suggests that pluripotency of ES cells can be maintained simply by inhibiting the endogenous activity of differentiation-inducing proteins, rather than also activating specific self-renewal pathways. Thus, inhibiting the effects of endogenously expressed inducers of cell death and differentiation may be sufficient for ES cell selfrenewal. This hypothesis is supported by a study by Ying et al [25], in which a combination of glycogen synthase kinase-3 (GSK-3) inhibitor, CHIR99021 and mitogen-activated protein kinase (MEK) inhibitor, PD0325901, could maintain long-term self-renewal of mESCs in the absence of exogenous cytokines [25]. Other small molecules which has been used to maintain mouse ES cells in pluripotent state include PD98059, a MEK inhibitor, 6Bromoindirubin-3'-oxime (BIO), another GSK-3 inhibitor/Wnt signaling activator, and IQ-1, a modulator of Wnt/CBP signalling (Table 1) [20].

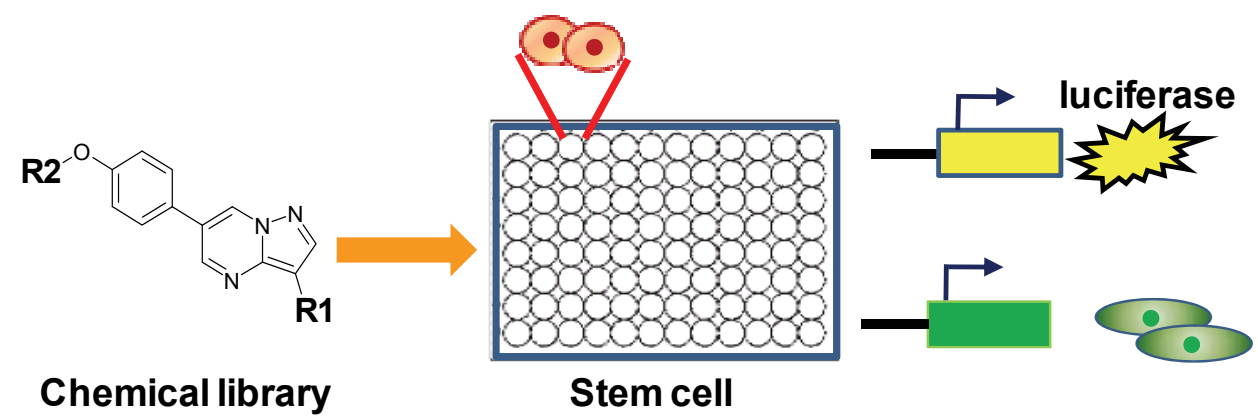

Fig. 2. Overview of the high-throughput screen to identify small molecules that promote cardiomyogenesis in pluripotent stem cells. Small molecules from a chemical library are added to the microtiter plates containing stem cells engineered to express either the luciferase or a fluorescent protein under a cardiac-specific promoter. After several days of differentiation, the potential procardiogenic hits are identified based on their ability to induce luciferase activity or fluorescence.

In addition to synthetic small molecules, certain physiological small molecules are capable of enhancing ES self-renewal. For example, Chen, et al. showed evidence that vitamin A (retinol) can promote self-renewal of mES cells in feeder-free conditions by modulating Nanog expression [26], a major transcription factor required for pluripotency. In addition, Garcia-Gonzaolo et al demonstrated that the positive effects of Knock-Out Serum Replacement (KOSR) on hESC self-renewal are mediated in part through albuminassociated lipids, although the direct mechanism remains unclear [27].

Thus far, a number of synthetic small molecules that promote self-renewal of mouse ES cells have been discovered, but none are known to support long-term maintenance of human ESCs or iPSCs in chemically defined, animal product-free conditions. Given increasing emphasis on human stem cells and the prospect for cell-based therapeutics, there is a substantial unmet demand for small molecules for maintenance of human pluripotent stem cells.

\section{B. Small molecules for cellular reprogramming}

In many respects, iPS cells are molecularly and functionally indistinguishable from ES cells. Like ES cells, they are pluripotent and capable of differentiating into every cell type in the 
body [8-10, 12]. The early cellular reprogramming methodologies involved viral vectormediated transduction of the combinations of either Sox2, Oct4, Klf4 and c-Myc 9, the socalled "Yamanaka Factors", or of Sox2, Oct4, Lin28 and Nanog (SOLN) [10]. It is now known that Oct4, Sox2 and Klf4 are sufficient for reprogramming [28], with the remaining three factors serving to increase reprogramming efficiency. Since the initial breakthrough in mouse embryonic fibroblasts, a number of cell types from variety of mammalian species have been successfully reprogrammed into iPS cells [10,12].

Although revolutionary, the early efforts in cellular reprogramming had critical limitations. First, the use of lentiviral and retroviral vectors for gene transduction raised the specter of oncogenesis, particularly since these early reprogramming methods resulted in permanent genomic integration of known oncogenes (c-Myc and klf4). Second, the early cellular reprogramming efforts were extremely inefficient, with only .0006 to $0.02 \%$ of transduced cells becoming iPS cells, [9, 10, 29]. Subsequent refinements, such as the plasmid-based, protein-based and modified RNA-based strategies, have led to successful virus-free, integration-free methods for cellular reprogramming [30-33]. Despite these successes, reprogramming remains a largely mysterious and inefficient process.

There have been important breakthroughs in the use of small molecules to enhance the efficiency of cellular reprogramming (Table 2). For example, recognizing that cellular reprogramming involves wholesale epigenetic changes, Melton and colleagues used valproic acid (VPA), a small molecule histone deacetylase (HDAC) inhibitor, to dramatically improve the reprogramming efficiency by 100 -fold without the use of c-Myc in the reprogramming cocktail [34]. In a related approach targeting the epigenetic machinery, Ding and colleagues used a G9a histone methyltransferase inhibitor, BIX01294, to substantially increase reprogramming efficiency of Sox2-expressing mouse neural progenitor cells (NPCs) transduced with just two factors, Oct4 and Klf4 (OK), to levels obtained with all four Yamanaka factors [35]. In a follow-up screen for small molecules that could synergize with BIX01294 to promote reprogramming in mouse embryonic fibroblasts transduced with Oct4 and Klf4, Ding and colleagues discovered that RG108, a DNA methyltransferase inhibitor, and BayK8644, an L-type calcium channel agonist, could each substantially enhance the reprogramming even in the absence of exogenous Sox2 [36]. In another approach, Eggan and colleagues sought to identify small molecules that could replace one or more of the reprogramming factors, reasoning that such an approach would not only reduce potential safety concerns but also enhance reprogramming efficiency. In a screen for small molecules that could replace Sox2 in the reprogramming cocktail, Eggan and colleagues identified a small molecule TGF- $\beta$ signaling inhibitor, renamed RepSox, which promotes reprogramming via the induction of Nanog, a transcription factor known to be critical for self-renewal of ES cells [37]. The findings that an L-type calcium channel agonist and a TGF- $\beta$ inhibitor could enhance reprogramming and bypass the need for Sox 2 transduction suggests that a focused approach targeting specific cell signal transduction pathways could contribute to further improvements in reprogramming efficiency. Chemical biological approaches to enhance reprogramming efficiencies have been successfully applied to human somatic cells. For example, a combination of the small molecules SB431542 (an ALK5 inhibitor), PD0325901 (a MEK inhibitor), and thiazovivin (which improves the survival of hESCs upon trypsinization) was shown to improve reprogramming efficiency of human fibroblasts by 200-fold [38]. These chemical biological efforts, in conjunction with improvements in our understanding of the fundamental 
mechanism of cellular reprogramming and epigenetic modifications, will lead to continual improvements in reprogramming methodologies, which will help move the iPSC field closer to the clinic.

\section{Small molecules for directing stem cell differentiation toward cardiomyogenesis.}

For the same reasons that small molecules are proving to be so useful for maintaining stem cell self-renewal and enhancing cellular reprogramming, small molecules will play an important role in directing differentiation of pluripotent stem cells toward the desired cell lineages as well. In principle, small molecules could be used for scaled-up production of stem cell-derived tissues for pharmaceutical testing, clinical diagnostics and even patientspecific cell replacement therapies. Importantly, small molecules can be developed for use as pharmacologicals to boost the heart repair and function following stem cell transplantations. Given the enormous potential of stem cells with respect to cardiovascular medicine, there has been significant interest in identifying small molecules that can promote differentiation of pluripotent stem cells toward cardiomyocytic development (Table 3).

A general approach to identify small molecules that promote cardiac development requires high-throughput screens for small molecules that induce cardiomyogenesis in various cultured stem cell models (Figure 2). In once such chemical screen, ascorbic acid (vitamin C) was found to significantly increase cardiomyogenesis of mouse ESCs. The precise mechanism by which ascorbic acid promotes cardiomyogenesis remains unknown, but it does not appear to involve ascorbic acid's well-known antioxidant activity, as other antioxidants like 4,5,-dihyroxyl-1,3,-benzene-disulfonic acid (Tiron) vitamin E, and Nacetylcysteine were not effective in inducing cardiomyogenesis under identical conditions [39]. A class of compounds named Cardiogenols is another example of procardiogenic small molecules identified in high-throughput screening (HTS) using ES cells. Treatment of mouse ES cells with Cardiogenol $\mathrm{C}$ during the initial 3 days of differentiation resulted in greater than $50 \%$ of cells expressing the a-MHC gene and greater than $90 \%$ of cells expressing GATA-4 at day 7 of differentiation [40]. While small molecules, like Cardiogenols, which are identified in HTS have great potential, one caveat is that procardiogenic effects of such compounds can vary depending on culturing conditions [41]. Nonetheless, Schneider and colleagues recently identified a class of small molecules, called Shz for sulfonyl-hydrazones, in a large-scale chemical screen using a Nkx2.5 promoterdependent luciferase reporter in pluripotent P19CL6 mouse embryonal carcinoma cell lines [42]. The Shz compounds potently induced expression of cardiac markers Nkx-2.5, Myocardin, Troponin-I and sarcomeric a-Tropomyosin in a number of stem cells and progenitor cells. Interestingly, pretreatment of human mobilized peripheral blood mononuclear cells (M-PBMCs) with the Shz compounds followed by transplantation into injured rat heart lead to significant enhancement in myocardial repair. While the precise mechanism of action is unknown, the Shz compounds could prove to be clinically useful as an adjunct to cell-based therapies to repair damaged heart.

A second general approach to identifying small molecules that promote cardiomyogenesis involves testing known small molecules that selectively modulate key developmental signaling pathways. Since it is generally accepted that in vitro cardiomyogenesis in ES cells or iPS cells recapitulates many of the events during heart formation in the embryo, using small molecules to selectively modulate specific cell signaling events that govern embryonic development may be an effective approach to promote cardiomyogenesis in stem cells. 
Studies in embryonic heart development highlighted the importance of signaling by Activins and bone morphogenetic proteins (BMPs), both members of the transforming growth factor $\beta$ (TGF- $\beta$ ) superfamily, in the formation of mesoderm and in specification of myocardial lineages [43-49]. Indeed, the Activin and BMP signaling pathways play key roles in the formation of cardiac cells in both human and mouse ES cell models [47, 49]. Based on the procardiogenic effects of the natural extracellular BMP antagonist Noggin on ES cells, Hong and colleagues demonstrated that dorsomorphin, a selective small molecular inhibitor of BMP signaling, was one of the most robust chemical inducers of cardiomyogenesis in mouse ES cells, increasing the yield of cardiomyoctyes by up to 50-fold [50]. Surprisingly, dorsomorphin treatment limited to the first 24-hours of ES cell differentiation, fully 2 days prior to the robust expression of the early mesoderm marker BryT, was sufficient for massive cardiac induction. This, together with the fact that the robust cardiac induction occurs in the absence of similar induction of BryT or cardiac progenitor maker Mesp1, suggests that the procardiogenic effects of dorsomorphin is mediated by an still unknown mechanism.

Studies of in vitro cardiomyogenesis and in vivo embryonic heart development have revealed the central role of canonical Wnt/ $\beta$-catenin signaling [51, 52]. As in many other contexts, Wnt signaling has complex stage-specific effects on cardiomyocyte formation [53, 54]. At the early stages of mouse ES cell differentiation, Wnt activation promotes cardiomyogenesis presumably by augmenting the formation of mesodermal cells committed to a cardiac lineage [55]. But, after the mesoderm formation, Wnt signaling prevents differentiation of committed cells into cardiomyocytes $[53,56]$. Similar time-dependent biphasic effects of Wnt signaling on cardiomyogenesis are also noted in human ES cells [57].

Given the importance of Wnt/ / $\beta$-catenin signaling in cardiomyogenesis, it is not surprising then that selective modulators of this pathway have a strong impact on in vitro cardiomyogenesis. For example, 6-bromoindirubin-3'-oxime (BIO), a selective inhibitor of GSK-3 which activates Wnt/ $\beta$-catenin signaling, significantly induced cardiomyocyte formation in mouse ES cells when treatment occurred early (day 0 to 3 ) in ES cell differentiation. In contrast, late addition of BIO (starting at day 5) completely abolished the expression of cardiac markers and the appearance of spontaneously contracting embryoid bodies [56]. Interestingly, the same compound BIO was identified in a HTS screen for small molecules that expand postnatal Isl1+ cardiovascular progenitor cells [58], and it was also shown to promote proliferation of neonatal and adult rat cardiomyocytes [59]. These intriguing results suggest that small molecule Wnt pathway activators like BIO may one day be used as pharmacological agents to restore function in the diseased heart.

Small molecule Wnt signaling inhibitors may also be useful for promoting cardiac development. For example, Hong and colleagues found that a selective small molecule inhibitor of Wnt/ $\beta$-catenin signaling can also markedly induce cardiomyogenesis in mouse ES cells. When this inhibitor was administered at day 3, immediately after the formation of mesoderm, there was a nearly 30-fold induction of cardiomyocyte formation at the expense of other mesodermal lineages such as the endothelial and smooth muscle cell lineages (in press). These results hint that small molecule Wnt inhibitors could be useful for promoting cardiac differentiation of multipotent cardiovascular progenitor cell types.

While small molecules have been successful in directing differentiation of embryonic stem cells toward the cardiovascular lineage, accumulating evidence suggests that similar efforts using iPS cells face additional hurdles. For example, efficiency of cardiomyogenesis in 
mouse and human iPS cells are significantly lower than for ES cells of respective species [60, 61]. The mechanism for this appears to be the recently discovered epigenetic memory, which stipulates reprogrammed cells tend to differentiate preferentially into tissue types from which they were originally derived [62]. Epigenetic memory is particularly germane to the cardiovascular field since human adult cardiomyocytes are not suitable substrates for reprogramming. Given the breathtakingly rapid advances in the field, however, we anticipate small molecules that can overcome epigenetic memory to facilitate differentiation of iPS cells into cardiovascular cell types will soon be found.

\section{Summary}

Recent breakthroughs in cellular reprogramming, coupled with the steady stream of advances in stem cell biology, have raised expectations for patient-derived stem cells. It is conceivable that they will someday be used for clinical diagnostic testing, drug discovery, and regenerative medicine to treat human heart failure, a common yet often fatal condition with no known cure. However, as outlined in this chapter, numerous hurdles must be overcome before the regenerative potential of stem cells can be fully harnessed. Increasingly, small molecules are being used to successfully overcome each of these challenges. Therefore, it seems reasonable to anticipate that small molecules will prove to be essential for translating basic stem cell discoveries into future regenerative therapies.

\begin{tabular}{|c|c|c|c|}
\hline Molecule & Name & Target & reference \\
\hline & Pluripotin/SC1 & $\begin{array}{l}\text { Dual inhibitor of } \\
\text { RasGAP/ERK1 }\end{array}$ & $\begin{array}{l}\text { Chen, et al., PNAS } 2006 \\
\text { Ref } 18\end{array}$ \\
\hline & CHIR99021 & GSK3 inhibitor & $\begin{array}{l}\text { Ying et al., Nature } 2008 \\
\text { Ref } 19\end{array}$ \\
\hline & PD0325901 & MEK inhibitor & $\begin{array}{l}\text { Ying et al., Nature } 2008 \\
\text { Ref } 19\end{array}$ \\
\hline & IQ-1 & $\begin{array}{l}\text { Phosphatase PP2A } \\
\text { Inhibitor (Wnt } \\
\text { modulator) }\end{array}$ & $\begin{array}{l}\text { Miyabayashi et al., PNAS } 2007 \\
\text { Ref } 20\end{array}$ \\
\hline
\end{tabular}

Table 1. Small molecules for maintenance of pluripotent stem cells 


\begin{tabular}{|c|c|c|c|}
\hline Molecule & Name & Target & reference \\
\hline & BIX01294 & G9a HMTase & $\begin{array}{l}\text { Shi et al., Cell stem cell } 2008 \\
\text { Ref } 35\end{array}$ \\
\hline & ValproicAcid & $\begin{array}{l}\text { Histone deacetylase } \\
\text { (HDAC) inhibitor }\end{array}$ & $\begin{array}{l}\text { Huangfu et al.,Nature Biotech , } 2008 \\
\text { Ref } 34\end{array}$ \\
\hline & SB431542 & TGF $\beta$ inhibitor & $\begin{array}{l}\text { Lin et al., Nature method, } 2009 \\
\text { Ref } 38\end{array}$ \\
\hline & Thiazovivin & unknown & $\begin{array}{l}\text { Lin et al., Nature method, } 2009 \\
\text { Ref } 38\end{array}$ \\
\hline & RG108 & $\begin{array}{l}\text { DNA methyltransferase } \\
\text { inhibitor }\end{array}$ & $\begin{array}{l}\text { Shi et al., Cell stem cell } 2008 \\
\text { Ref } 35\end{array}$ \\
\hline & BayK8644 & $\begin{array}{l}\text { L-type calcium } \\
\text { channel agonist }\end{array}$ & $\begin{array}{l}\text { Shi et al., Cell stem cell } 2008 \\
\text { Ref } 35\end{array}$ \\
\hline & RepSox & TGF $\beta$ inhibitor & $\begin{array}{l}\text { ichida, et al., Cell stem cell } 2009 \\
\text { Ref } 37\end{array}$ \\
\hline
\end{tabular}

Table 2. Small molecules to enhance reprogramming efficiency 


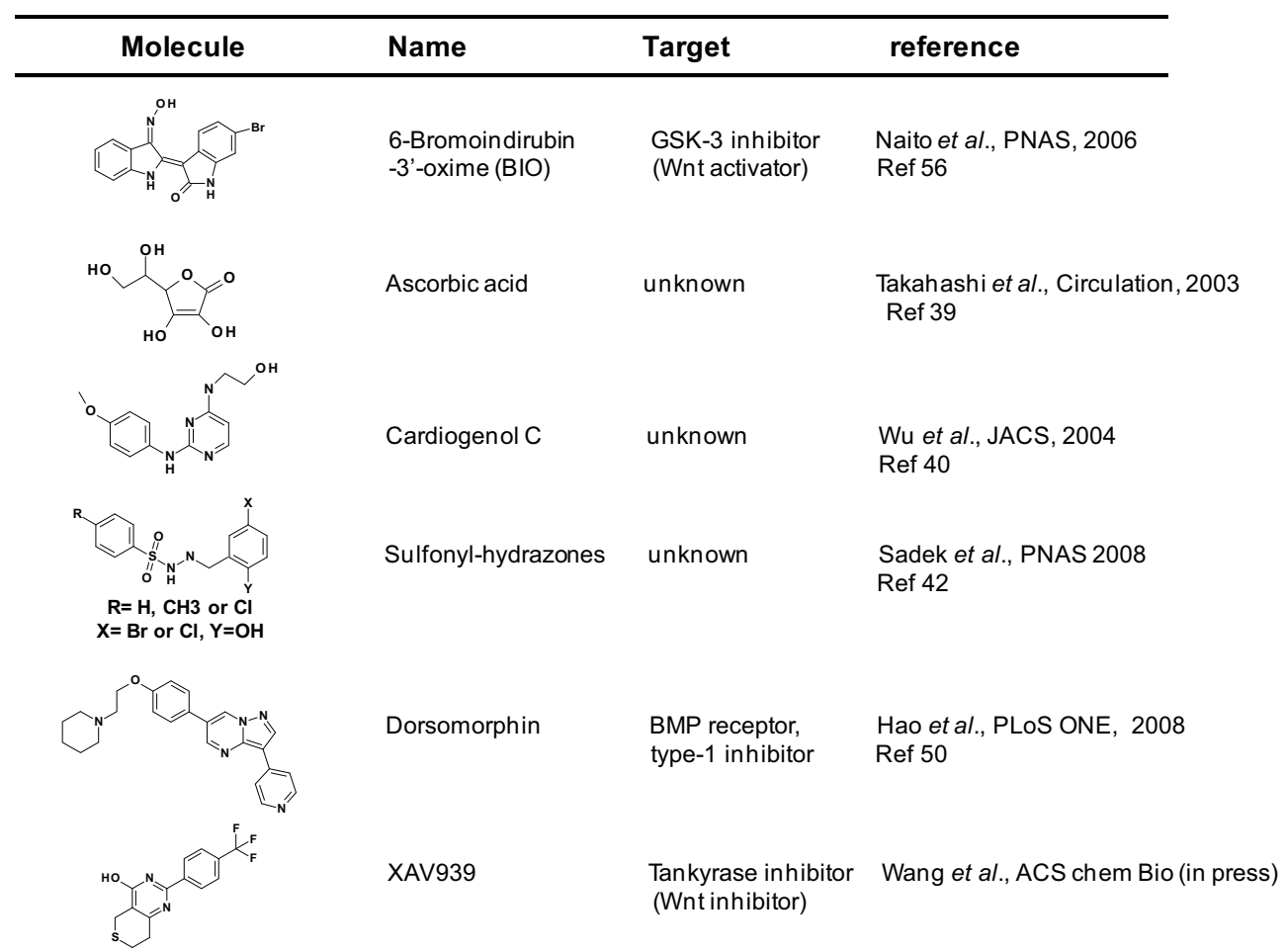

Table 3. Small molecules to promote cardiomyogenesis in pluripotent stem cells. 


\section{Reference}

[1] Hsieh, P.C., et al., Evidence from a genetic fate-mapping study that stem cells refresh adult mammalian cardiomyocytes after injury. Nat Med, 2007. 13(8): p. 970-4.

[2] Bergmann, O., et al., Evidence for cardiomyocyte renewal in humans. Science, 2009. 324(5923): p. 98-102.

[3] Hierlihy, A.M., et al., The post-natal heart contains a myocardial stem cell population. FEBS Lett, 2002. 530(1-3): p. 239-43.

[4] Bearzi, C., et al., Identification of a coronary vascular progenitor cell in the human heart. Proc Natl Acad Sci U S A, 2009. 106(37): p. 15885-90.

[5] Tillmanns, J., et al., Formation of large coronary arteries by cardiac progenitor cells. Proc Natl Acad Sci U S A, 2008. 105(5): p. 1668-73.

[6] Thomson, J.A., et al., Embryonic stem cell lines derived from human blastocysts. Science, 1998. 282(5391): p. 1145-7.

[7] Takahashi, K. and S. Yamanaka, Induction of pluripotent stem cells from mouse embryonic and adult fibroblast cultures by defined factors. Cell, 2006. 126(4): p. 663-76.

[8] Okita, K., T. Ichisaka, and S. Yamanaka, Generation of germline-competent induced pluripotent stem cells. Nature, 2007. 448(7151): p. 313-7.

[9] Okita, K., et al., Generation of mouse induced pluripotent stem cells without viral vectors. Science, 2008. 322(5903): p. 949-53.

[10] Takahashi, K., et al., Induction of pluripotent stem cells from adult human fibroblasts by defined factors. Cell, 2007. 131(5): p. 861-72.

[11] Wernig, M., et al., In vitro reprogramming of fibroblasts into a pluripotent ES-cell-like state. Nature, 2007. 448(7151): p. 318-24.

[12] $\mathrm{Yu}$, J., et al., Induced pluripotent stem cell lines derived from human somatic cells. Science, 2007. 318(5858): p. 1917-20.

[13] Vallier, L., M. Alexander, and R.A. Pedersen, Activin/Nodal and FGF pathways cooperate to maintain pluripotency of human embryonic stem cells. J Cell Sci, 2005. 118(Pt 19): p. 4495-509.

[14] Sakamoto, N., et al., Bovine apolipoprotein B-100 is a dominant immunogen in therapeutic cell populations cultured in fetal calf serum in mice and humans. Blood, 2007. 110(2): p. 501-8.

[15] Cheng, J., et al., Improved generation of C57BL/6J mouse embryonic stem cells in a defined serum-free media. Genesis, 2004. 39(2): p. 100-4.

[16] Ludwig, T.E., et al., Derivation of human embryonic stem cells in defined conditions. Nat Biotechnol, 2006. 24(2): p. 185-7.

[17] Mallon, B.S., et al., Toward xeno-free culture of human embryonic stem cells. Int J Biochem Cell Biol, 2006. 38(7): p. 1063-75.

[18] Chen, S., et al., Self-renewal of embryonic stem cells by a small molecule. Proc Natl Acad Sci U S A, 2006. 103(46): p. 17266-71.

[19] Ying, Q.L., et al., BMP induction of Id proteins suppresses differentiation and sustains embryonic stem cell self-renewal in collaboration with STAT3. Cell, 2003. 115(3): p. 281-92. 
[20] Miyabayashi, T., et al., Wnt/beta-catenin/CBP signaling maintains long-term murine embryonic stem cell pluripotency. Proc Natl Acad Sci U S A, 2007. 104(13): p. 566873.

[21] Niwa, H., et al., Self-renewal of pluripotent embryonic stem cells is mediated via activation of STAT3. Genes Dev, 1998. 12(13): p. 2048-60.

[22] Paling, N.R., et al., Regulation of embryonic stem cell self-renewal by phosphoinositide 3-kinase-dependent signaling. J Biol Chem, 2004. 279(46): p. 48063-70.

[23] Qi, X., et al., BMP4 supports self-renewal of embryonic stem cells by inhibiting mitogenactivated protein kinase pathways. Proc Natl Acad Sci U S A, 2004. 101(16): p. 602732.

[24] Burdon, T., et al., Suppression of SHP-2 and ERK signalling promotes self-renewal of mouse embryonic stem cells. Dev Biol, 1999. 210(1): p. 30-43.

[25] Ying, Q.L., et al., The ground state of embryonic stem cell self-renewal. Nature, 2008. 453(7194): p. 519-23.

[26] Chen, L. and J.S. Khillan, Promotion of feeder-independent self-renewal of embryonic stem cells by retinol (vitamin A). Stem Cells, 2008. 26(7): p. 1858-64.

[27] Garcia-Gonzalo, F.R. and J.C. Izpisua Belmonte, Albumin-associated lipids regulate human embryonic stem cell self-renewal. PLoS One, 2008. 3(1): p. e1384.

[28] Nakagawa, M., et al., Generation of induced pluripotent stem cells without Myc from mouse and human fibroblasts. Nat Biotechnol, 2008. 26(1): p. 101-6.

[29] Stadtfeld, M., et al., Induced pluripotent stem cells generated without viral integration. Science, 2008. 322(5903): p. 945-9.

[30] Cho, H.J., et al., Induction of pluripotent stem cells from adult somatic cells by proteinbased reprogramming without genetic manipulation. Blood, 2010. 116(3): p. 386-95.

[31] Okita, K., et al., Generation of mouse-induced pluripotent stem cells with plasmid vectors. Nat Protoc, 2010. 5(3): p. 418-28.

[32] Warren, L., et al., Highly efficient reprogramming to pluripotency and directed differentiation of human cells with synthetic modified mRNA. Cell Stem Cell, 2010. 7(5): p. 618-30.

[33] Zhou, H., et al., Generation of induced pluripotent stem cells using recombinant proteins. Cell Stem Cell, 2009. 4(5): p. 381-4.

[34] Huangfu, D., et al., Induction of pluripotent stem cells by defined factors is greatly improved by small-molecule compounds. Nat Biotechnol, 2008. 26(7): p. 795-7.

[35] Shi, Y., et al., A combined chemical and genetic approach for the generation of induced pluripotent stem cells. Cell Stem Cell, 2008. 2(6): p. 525-8.

[36] Shi, Y., et al., Induction of pluripotent stem cells from mouse embryonic fibroblasts by Oct 4 and Klf4 with small-molecule compounds. Cell Stem Cell, 2008. 3(5): p. 568-74.

[37] Ichida, J.K., et al., A small-molecule inhibitor of tgf-Beta signaling replaces sox2 in reprogramming by inducing nanog. Cell Stem Cell, 2009. 5(5): p. 491-503.

[38] Lin, T., et al., A chemical platform for improved induction of human iPSCs. Nat Methods, 2009. 6(11): p. 805-8.

[39] Takahashi, T., et al., Ascorbic acid enhances differentiation of embryonic stem cells into cardiac myocytes. Circulation, 2003. 107(14): p. 1912-6. 
[40] Wu, X., et al., Small molecules that induce cardiomyogenesis in embryonic stem cells. J Am Chem Soc, 2004. 126(6): p. 1590-1.

[41] Jasmin, et al., Chemical induction of cardiac differentiation in p19 embryonal carcinoma stem cells. Stem Cells Dev, 2010. 19(3): p. 403-12.

[42] Sadek, H., et al., Cardiogenic small molecules that enhance myocardial repair by stem cells. Proc Natl Acad Sci U S A, 2008. 105(16): p. 6063-8.

[43] Moore, C.S., C.H. Mjaatvedt, and J.D. Gearhart, Expression and function of activin beta A during mouse cardiac cushion tissue formation. Dev Dyn, 1998. 212(4): p. 548-62.

[44] Nakajima, Y., et al., Mechanisms involved in valvuloseptal endocardial cushion formation in early cardiogenesis: roles of transforming growth factor (TGF)-beta and bone morphogenetic protein (BMP). Anat Rec, 2000. 258(2): p. 119-27.

[45] Jones, C.M., K.M. Lyons, and B.L. Hogan, Involvement of Bone Morphogenetic Protein4 (BMP-4) and Vgr-1 in morphogenesis and neurogenesis in the mouse. Development, 1991. 111(2): p. 531-42.

[46] Winnier, G., et al., Bone morphogenetic protein-4 is required for mesoderm formation and patterning in the mouse. Genes Dev, 1995. 9(17): p. 2105-16.

[47] Johansson, B.M. and M.V. Wiles, Evidence for involvement of activin A and bone morphogenetic protein 4 in mammalian mesoderm and hematopoietic development. Mol Cell Biol, 1995. 15(1): p. 141-51.

[48] Gadue, P., et al., Wnt and TGF-beta signaling are required for the induction of an in vitro model of primitive streak formation using embryonic stem cells. Proc Natl Acad Sci U S A, 2006. 103(45): p. 16806-11.

[49] Klaus, A., et al., Distinct roles of Wnt/beta-catenin and Bmp signaling during early cardiogenesis. Proc Natl Acad Sci U S A, 2007. 104(47): p. 18531-6.

[50] Hao, J., et al., Dorsomorphin, a selective small molecule inhibitor of BMP signaling, promotes cardiomyogenesis in embryonic stem cells. PLoS One, 2008. 3(8): p. e2904.

[51] Cohen, E.D., Y. Tian, and E.E. Morrisey, Wnt signaling: an essential regulator of cardiovascular differentiation, morphogenesis and progenitor self-renewal. Development, 2008. 135(5): p. 789-98.

[52] Tzahor, E., Wnt/beta-catenin signaling and cardiogenesis: timing does matter. Dev Cell, 2007. 13(1): p. 10-3.

[53] Ueno, S., et al., Biphasic role for Wnt/beta-catenin signaling in cardiac specification in zebrafish and embryonic stem cells. Proc Natl Acad Sci U S A, 2007. 104(23): p. 9685-90.

[54] Kwon, C., et al., Canonical Wnt signaling is a positive regulator of mammalian cardiac progenitors. Proc Natl Acad Sci U S A, 2007. 104(26): p. 10894-9.

[55] Soonpaa, M.H., et al., Formation of nascent intercalated disks between grafted fetal cardiomyocytes and host myocardium. Science, 1994. 264(5155): p. 98-101.

[56] Naito, A.T., et al., Developmental stage-specific biphasic roles of Wnt/beta-catenin signaling in cardiomyogenesis and hematopoiesis. Proc Natl Acad Sci U S A, 2006. 103(52): p. 19812-7.

[57] Paige, S.L., et al., Endogenous Wnt/beta-catenin signaling is required for cardiac differentiation in human embryonic stem cells. PLoS One, 2010. 5(6): p. e11134. 
[58] Qyang, Y., et al., The renewal and differentiation of Isl1+ cardiovascular progenitors are controlled by a Wnt/beta-catenin pathway. Cell Stem Cell, 2007. 1(2): p. 165-79.

[59] Tseng, A.S., F.B. Engel, and M.T. Keating, The GSK-3 inhibitor BIO promotes proliferation in mammalian cardiomyocytes. Chem Biol, 2006. 13(9): p. 957-63.

[60] Mauritz, C., et al., Generation of functional murine cardiac myocytes from induced pluripotent stem cells. Circulation, 2008. 118(5): p. 507-17.

[61] Zhang, J., et al., Functional cardiomyocytes derived from human induced pluripotent stem cells. Circ Res, 2009. 104(4): p. e30-41.

[62] Kim, K., et al., Epigenetic memory in induced pluripotent stem cells. Nature, 2010. 467(7313): p. 285-90. 


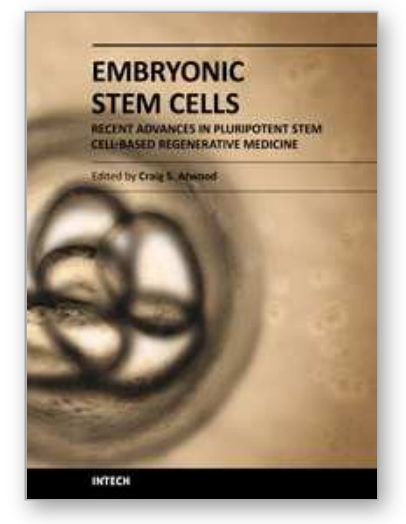

\section{Embryonic Stem Cells - Recent Advances in Pluripotent Stem Cell- Based Regenerative Medicine}

Edited by Prof. Craig Atwood

ISBN 978-953-307-198-5

Hard cover, 410 pages

Publisher InTech

Published online 26, April, 2011

Published in print edition April, 2011

Pluripotent stem cells have the potential to revolutionise medicine, providing treatment options for a wide range of diseases and conditions that currently lack therapies or cures. This book describes recent advances in the generation of tissue specific cell types for regenerative applications, as well as the obstacles that need to be overcome in order to recognize the potential of these cells.

\section{How to reference}

In order to correctly reference this scholarly work, feel free to copy and paste the following:

Jijun Hao, Li Zhou and Charles C. Hong (2011). Chemical Biology of Pluripotent Stem Cells: Focus on Cardiomyogenesis, Embryonic Stem Cells - Recent Advances in Pluripotent Stem Cell-Based Regenerative Medicine, Prof. Craig Atwood (Ed.), ISBN: 978-953-307-198-5, InTech, Available from:

http://www.intechopen.com/books/embryonic-stem-cells-recent-advances-in-pluripotent-stem-cell-basedregenerative-medicine/chemical-biology-of-pluripotent-stem-cells-focus-on-cardiomyogenesis

\section{INTECH}

open science | open minds

\author{
InTech Europe \\ University Campus STeP Ri \\ Slavka Krautzeka 83/A \\ 51000 Rijeka, Croatia \\ Phone: +385 (51) 770447 \\ Fax: +385 (51) 686166 \\ www.intechopen.com
}

\author{
InTech China \\ Unit 405, Office Block, Hotel Equatorial Shanghai \\ No.65, Yan An Road (West), Shanghai, 200040, China \\ 中国上海市延安西路65号上海国际贵都大饭店办公楼 405 单元 \\ Phone: +86-21-62489820 \\ Fax: $+86-21-62489821$
}


(C) 2011 The Author(s). Licensee IntechOpen. This chapter is distributed under the terms of the Creative Commons Attribution-NonCommercialShareAlike-3.0 License, which permits use, distribution and reproduction for non-commercial purposes, provided the original is properly cited and derivative works building on this content are distributed under the same license. 